\section{A case of 2-methylacetoacetyl CoA thiolase deficiency with coincidental chromosome abnormalities}

Eight cases of confirmed or presumed 2-methylacetoacetyl CoA thiolase deficiency have been reported to date and all are consistent with an autosomal recessive mode of inheritance. Our proband, a female, is the first child of unrelated Caucasian parents who also have a healthy male child. She presented aged 5 months with vomiting, pyrexia, dehydration, and a metabolic acidosis associated with increased urinary excretion of 2-methyl3-hydroxybutyrate, tiglyglycine, 2-methylacetoacetate, 2-methyl-3-ketobutyrate, (E)-2-methylglutaconate, and 2-3-dimethyl-3-hydroxyglutarate. Cultured fibroblasts revealed a total deficiency in the activity of 2-methylacetoacetyl CoA thiolase (EC.2.3.1.9) with normal activities of all other thiolases. The present policy in our laboratory is to karyotype all cultured fibroblasts. This revealed in her case a 47, XXX karyotype. Phytohaemagglutinin stimulated lymphocytes from the patient exhibited a mosaic karyotype of $45, \mathrm{X} / 47, \mathrm{XXX}(25 \% / 75 \%)$. At present ( 3 years 9 months) she is well and shows none of the external stigmata of Turner's syndrome but may well experience problems at the onset of puberty. The frequency of acidotic attacks has decreased on reduction of her dietary protein intake.

A family has also been reported in which one male sib had no detectable enzyme activity while his brother had a level of activity consistent with the heterozygous state. ${ }^{2}$ This would suggest that this disorder is inherited in an autosomal mode and therefore that the chromosomal

Received for publication 31 December 1983. Accepted for publication 11 January 1984. abnormalities in our patient are unlikely to be related to the biochemical disorder.

Chromosome abnormalities have been detected in patients with inborn errors of metabolism and in some cases the biochemical and cytogenetic abnormalities have been directly linked. ${ }^{3}$ Our experience with this case indicates the value of karyotyping cells cultured for biochemical tests from patients with inborn errors of metabolism.

R G F GraY*, G W Lowther†, J M LitTlewood $\ddagger$, B Middleton $\S$, AND M J BenNeti\|

*University Sub-Department of Medical Genetics, + Centre for Human Genetics, Sheffield S10 5DN; $\ddagger$ Department of Paediatrics, St James's University Hospital, Leeds LS9 7TF;

§Department of Biochemistry, University of Nottingham Medical School, Nottingham NG7 2UH; and $\|$ Department of Chemical Pathology, Children's Hospital, Sheffield S10 $2 \mathrm{TH}$.

\section{References}

1 Middleton B, Gray RGF, Bennett MJ. Two cases of $\beta$-ketothiolase deficiency: a comparison. J Inher Metab Dis (in press).

2 Schutgens RBH, Middleton B, Van de Blij JF, et al. Betaketothiolase deficiency in a family confirmed by in vitro enzymatic assays in fibroblasts. Eur $J$ Pediatr 1982; 139:39-42.

${ }^{3}$ Tiepoloi L, Zuffardi O, Fraccaro M, et al. Assignment by deletion maping of the steroid sulphatase X-linked ichthyosis locus to Xp223. Hum Genet 1980;54:205-6.

Correspondence and requests for reprints to $\mathrm{Dr} R \mathrm{G} \mathrm{F}$ Gray, Centre for Human Genetics, University of Sheffield, Langhill, 117 Manchester Road, Sheffield S10 5DN. 